\title{
De-industrialization and entrepreneurship under monopolistic competition
}

\author{
By Albert G. Schweinberger ${ }^{\dagger}$ and Jens Suedekum ${ }^{a}$ \\ ${ }^{\dagger}$ University of Konstanz (deceased) \\ aHeinrich-Heine-University Düsseldorf, Düsseldorf Institute for Competition Economics (DICE), \\ Universitätsstrasse 1, 40225 Düsseldorf, Germany; e-mail: suedekum@dice.hhu.de
}

\begin{abstract}
This article offers a new mechanism to explain de-industrialization in response to a price increase of the manufactured good. In our trade model, one sector (agriculture) is perfectly competitive whilst the other (manufacturing) is monopolistically competitive. Both industries use skilled and unskilled labour as inputs. Entry into manufacturing requires a fixed cost in terms of skilled labour only. A rise in the market price for the differentiated goods raises both marginal revenue and the price of skilled labour, which affects the marginal cost of production and the entry cost. When short-run profits increase so that new manufacturing firms enter, fewer skilled workers are available for production purposes. This in turn may then lead to a decline in total manufacturing output. Our theoretical mechanism is jointly consistent with recent empirical observations on premature de-industrialization characterizing several Latin American and Asian countries and productive diversification as observed in various developing economies.
\end{abstract}

JEL classifications: F12, D43

\section{Introduction}

De industrialization, defined either as a fall in the share of industrial output in GDP or the share of industrial employment in total employment, and its short and long run term effects on growth and development are time honoured topics of a huge empirical and theor etical research effort since the seminal contributions by Kaldor (1966, 1967). Recently the topic has acquired a new dimension because some economists have focussed in their empir ical work on 'premature de industrialization', that is, de industrialization at a much lower level of per capita income than what is observed historically in today's advanced economies (see Dasgupta and Singh, 2007). A structural tendency of premature de industrialization appears to be evident in a number of countries in Latin America in the 1980s and 1990s. In Asian countries, de industrialization occurs in mature economies such as Hong Kong or Taipei, undoubtedly owing to a relocation of production to mainland China. On the other 
hand, there also exists some prima facie evidence that premature de industrialization exists in less mature Asian countries such as the Philippines, Indonesia, or India. ${ }^{1}$

What are the main causes of de industrialization? To shed some light on these highly im portant issues, we adopt a perspective based on a two sector general equilibrium model of an open economy with monopolistic competition. It seems to us that the many interesting results of the received literature on the causes and consequences of de industrialization not withstanding, our approach yields a number of novel insights. This is mainly due to the fact that monopolistic competition models allow us to capture in a relatively simple framework the interaction between the number of firms, firm size, and total industry output.

We develop a simple $2 \times 2$ general equilibrium model of a small open economy with two factors (skilled and unskilled labour) and two industries, one with perfect competition ('agriculture') and one with monopolistic competition ('manufacturing'). The basic tenet of our article is that setting up new manufacturing firms is an entrepreneurial activity that re quires special abilities. Only skilled labour is endowed with such abilities. In our model, both industries use both factors as inputs in production, but in manufacturing there is also a fixed input requirement of skilled workers per firm to act as entrepreneurs. This set up cost gives rise to non homotheticity, and the industry's overall factor intensity depends on the scale of manufacturing production.

Now consider an increase in the world relative price of manufacturing goods, which rep resents an improvement in the terms of trade if the country is a net exporter of manufactur ing varieties. According to the received literature, this should lead to an expansion of total industrial output. Yet due to changes in profits in the short run equilibrium, there may occur also an endogenous change in the number of firms. If the price increase has a suffi ciently strong positive effect on profits, additional firms enter the industry, that is, it in duces entrepreneurial activity.

Due to non homothetic production, this implies that more of the skilled labour must be used as a fixed input and therefore the effective endowment of skilled labour available for production purposes decreases. This decrease is the driving force behind the possible de in dustrialization result in our model. However, the price increase also entails the well known positive output price effect working into the opposite direction. Which effect dominates de pends, inter alia, on the relative sizes of three effects: (i) a novel generalized Rybczynski effect that captures the allocation of skilled labour to the setting up of firms relative to pro duction; (ii) the change in firms' profit margins (mark ups) relative to the induced change in factor prices, as captured by a concept called 'marginal profitability of setting up manu facturing firms' (MPS); and (iii) the magnitude of the standard short run output effect (SOE) that is well known from the received literature.

Previewing our main theoretical proposition, we show that the increase in the relative price of the manufactured good can lead to a decline in total manufacturing output (i.e., to de industrialization) if the former two effects are relatively large. We also show that induced entry and a decrease in the output per firm are necessary (but not sufficient) condi tions for de industrialization to occur.

Of course, our model is just one possible theory for de industrialization. There are sev eral others, including the recent contributions by Föllmi and Zweimüller (2008) and Murata (2009), which rely on very different mechanisms. We stress, however, that there is

1 Recent empirical contributions on these issues include Imbs and Wacziarg (2003), Debande (2006), Rodrik (2007), and Felipe and Estrada (2008). 
evidence from real world episodes of de industrialization that is consistent with the main features of our framework. For example, it is well documented that in some industries the adjustment to positive exogenous shocks takes place mainly at the extensive margin through setting up new firms rather than an increase in the output per firm. Klepper and Graddy (1990) typify the evolution of firm numbers and industry concentration in response to new market opportunities. During an early stage, they find that firms rush in to take ad vantage of the new opportunities. This is followed by a stage of a shake out that reduces the number of inefficient firms, see also Brandt et al. (2008). An entrepreneurial industry in our definition would thus be one in the early stage, where positive shocks generate entry, which might come with a reduction in overall industry output owing to the fixed set up costs.

Relatedly, Imbs and Wacziarg (2003) and Rodrik (2007) observe that growth amongst less developed countries (LDCs) typically comes with a process of 'productive diversifica tion' within the manufacturing sector. That is, as LDCs become more integrated into the world economy, and are exposed to increasing relative prices for modern sectors as empha sized in our model, they do not typically reinforce existing manufacturing specializations. Rather, they expand their production ranges and often build up new manufacturing activ ities. This is especially true for low income countries at the earliest stage of development. This expansion of the product range can be associated with the entry of new firms in our model. Owing to fixed set up costs, this expansion can come at least initially when the induced entry is strong with a reduction in total industrial output. This mechanism highlighted by our model is thus jointly consistent with the observation of premature de industrialization characterizing several Latin American and Asian countries (Dasgupta and Singh, 2007) on the one hand, and the 'productive diversification' (Imbs and Wacziarg, 2003; Rodrik, 2007) on the other hand.

The article is structured as follows. In Section 2 we discuss some related literature. Section 3 presents our basic model structure, and the main results are derived in Section 4. In Section 5, we draw some tentative conclusions.

\section{Relationship to the received literature}

The vast majority of monopolistic competition models in the literature relies simultaneously on two key assumptions: homothetic production and constant demand elasticity. Prominent examples include Krugman (1980) and Melitz (2003), who assume only a single production factor (labour) and preferences of the constant elasticity of substitution (CES) type, which in turn leads to iso elastic demands and constant mark ups charged by manu facturing firms.

Empirical work strongly suggests that non homothetic production is a highly realistic feature (McDonough, 1992), and an older literature (Helpman, 1980; Horn, 1983; Lawrence and Spiller, 1983; Chao and Takayama, 1990) has indeed started to look at non homothetic production in monopolistic competition models (also see Helpman and Krugman, 1985). ${ }^{2}$ Those contributions typically maintain the assumption of constant

2 Often, models with multiple factors maintain the assumption of homotheticity. See, for example, Bernard et al. (2007) or Markusen and Venables (2000), who assume differences in factor intensity across industries, but identical factor intensities in the fixed and variable input requirements within 
demand elasticity, however, and make no reference to the mechanism leading to de indus trialization that is described in this paper.

Building on the pioneering work by Krugman (1979), there has been a very active recent literature relaxing the CES assumption in monopolistic competition models. Prominent ex amples of such frameworks with endogenous mark ups include Ottaviano et al. (2002), Behrens and Murata (2007, 2012a,b), Melitz and Ottaviano (2008), Zhelobodko et al. (2012), and Behrens et al. (2014). Yet these models assume a single production factor.

In particular, Zhelobodko et al. (2012) develop a framework with a general class of additively separable preferences allowing for pro and anti competitive market size effects. Thus, unlike Krugman (1979), who only considers the pro competitive case, they also take into account the possibility that relative love of variety (the elasticity of the marginal utility of consumption) may fall as consumption rises. In such a case, an increase in the number of firms entails an increase in the market price via increasing mark ups (an anti competitive ef fect), which is counter intuitive but not an exotica (see Amir and Lambson, 2000; Chen and Riordan, 2007; Fabinger and Weyl, 2013).

In our article, we relax both assumptions simultaneously. That is, we allow for non homothetic production and variable demand elasticity, leading to endogenous mark ups. Similar to Zhelobodko et al. (2012), we do not specify a particular functional form for con sumer preferences but start from a general set up. Yet our approach is less general than theirs because we impose a positive elasticity of marginal revenue with respect to price an assumption that holds for most standard demand functions (including linear demands as in Ottaviano et al., 2002) but that may not hold in general. With respect to the technology and production side, however, our model is richer than that of Zhelobodko et al. (2012) be cause our economy features two types of labour and non homothetic manufacturing production.

A further related model is the recent contribution by Behrens and Murata (2012a). They assume specific consumer preferences with variable demand elasticity, thus leading to en dogenous mark ups. Individuals can differ in terms of labour efficiency, but the production function is still homothetic. In Behrens and Murata (2012a), trade integration can lead to a decrease in the mass of consumed (and produced) varieties in the rich country. Such an out come is broadly related to the notion of de industrialization that we have in mind. However, we propose a different mechanism in this article, which crucially hinges on vari able factor intensity in the manufacturing sector that depends on the industry's scale of pro duction (non homotheticity).

Finally, Neary $(2004,2009)$ lists a number of further shortcomings and lacunae of mon opolistic competition models. In several respects, our model follows standard practice and makes no attempt to improve on those criticized features. ${ }^{3}$ Yet at least for one item on Neary's list, we believe that our approach constitutes a small step forwards. Specifically, typical monopolistic competition models postulate that entrepreneurship and production require essentially the same production factors, homogeneous labour. In our model, we

industries. Our model, by contrast, features non homotheticity in the sense that factor intensity in the manufacturing sector depends on the scale of that industry.

3 For example, we ignore issues of strategic interaction between firms, even though Neary (2004, 2009) asks for a better reconciliation of monopolistic competition with the standard paradigm of in dustrial organization. 
make explicit that entrepreneurship and production have different factor intensities, which in turn generates a trade off for skilled labour that is needed for both types of activities.

\section{The model}

Consider a small open economy with exogenous endowments of unskilled labour $V_{1}$ and skilled labour $V_{2}$. All individuals have identical preferences. Production in industry 1 ('agri culture') is perfectly competitive. This good serves as the numéraire. Industry 2 ('manufac turing') is characterized by product differentiation and monopolistic competition. In total, there are $n$ symmetrical varieties, each produced by a single firm. Both industries use both factors as variable inputs. In addition, there is a fixed input requirement of $b$ units of skilled labour per manufacturing firm. The economy is described by the following five equations.

$$
\begin{aligned}
& a_{11}\left(w_{1}, w_{2}\right) X_{1}+a_{12}\left(w_{1}, w_{2}\right) X_{2} \quad V_{1} \\
& a_{21}\left(w_{1}, w_{2}\right) X_{1}+a_{22}\left(w_{1}, w_{2}\right) X_{2} \quad V_{2} \quad b \cdot n \equiv \tilde{V}_{2}(n) \\
& c_{1}\left(w_{1}, w_{2}\right) \equiv a_{11}\left(w_{1}, w_{2}\right) w_{1}+a_{21}\left(w_{1}, w_{2}\right) w_{2} \quad p_{1} \equiv 1 \\
& c_{2}\left(w_{1}, w_{2}\right) \equiv a_{12}\left(w_{1}, w_{2}\right) w_{1}+a_{22}\left(w_{1}, w_{2}\right) w_{2} \quad M R_{2}\left(p_{2}\right) \\
& {\left[p_{2} \quad c_{2}\left(w_{1}, w_{2}\right)\right] \cdot X_{2}\left(1, M R_{2}\left(p_{2}\right), V_{1}, \tilde{V}_{2}(n)\right) \quad w_{2} \cdot b \cdot n}
\end{aligned}
$$

The $a_{i j}$ 's are the unit input coefficients of factor $i$ in industry $j$, which depend on the fac tor prices $w_{1}$ and $w_{2}$. By $\tilde{V}_{2}(n)$ we denote the amount of skilled labour available for pro duction, which depends on the number of active manufacturing firms $n$. Equations (1) and (2) are factor market clearing conditions. Equation (3) represents the zero net profitability condition in the perfectly competitive industry. Equation (4) follows from profit maximiza tion in the monopolistically competitive industry and states that marginal costs $c_{2}\left(w_{1}, w_{2}\right)$ must equal marginal revenue $M R_{2}\left(p_{2}\right)$. Finally, eq. (5) is the zero profit condition in the manufacturing sector. It states that in the long run, operating profits equal total set up costs in that industry.

In eq. (5), $X_{j}$ stands for the total output in industry $j$. Note that $X_{2}(\cdot)$ is an aggregate supply function that is linear homogeneous in $V_{1}$ and $\tilde{V}_{2}$. It seems natural to assume that manufacturing production is intensive in skilled labour $\left(a_{22} / a_{21}>a_{12} / a_{11} \forall w_{1}, w_{2}\right)$. This entails that the equilibrium solution of eqs (1) (5) is unique, provided only that the Jacobean determinant of the production cost functions is non zero. We assume throughout the article that both goods are produced.

Our model has two useful properties. First, it focusses on the interactions between goods and factor markets assigning a special role to skilled labour as entrepreneurs. As shown later, many results hinge on the allocation of skilled labour between entrepreneurial tasks (the setting up of firms) and production. Second, it is more general than standard models of monopolistic competition because we do not assume a specific functional form for individ ual preferences; in particular, we do not postulate constant demand elasticity as is often done in the literature. This allows us to consider endogenous mark ups and the effects of price changes on firms' profit margins.

In what follows we investigate the effects of an increase in the price of a manufacturing variety, $p_{2}$, which is brought about by a rise in the world relative prices 
of the manufactured good. ${ }^{4}$ In doing so, we distinguish short and long run effects of this price change. The short run version of our model consists of eqs (1) to (4), and the com parative static results are then derived under the assumption that the number of firms $n$ in the manufacturing industry is fixed. All industry output adjustment occurs at the intensive margin in that case. In the long run perspective, the number of manufacturing firms $n$ is endogenous, and entry until the zero profit condition (5) is satisfied.

Before proceeding with the formal analysis, it is useful to point out the role played by the non homotheticity of production in our model. Note that the long run equilibrium con dition (5) implies that $p_{2} \quad c_{2}\left(w_{1}, w_{2}\right)+w_{2} b / x_{2}$, where $x_{2}$ denotes output per firm. This expression highlights that the overall factor intensity in manufacturing depends on the scale of production in that industry, because setting up firms requires only skilled labour.

\section{Results}

We consider an increase in the world price of manufacturing varieties $p_{2}$. The small country may be a net exporter or net importer of manufacturing varieties. Totally differentiating total industry output $X_{2}(\cdot)$, while leaving endowments unchanged, yields

$$
d X_{2}(\cdot) \quad \frac{\partial X_{2}}{\partial M R_{2}} \cdot \frac{\partial M R_{2}}{\partial p_{2}} \cdot d p_{2} \quad \frac{\partial X_{2}}{\partial \tilde{V}_{2}} \cdot b \cdot d n
$$

For notational convenience, we denote an elasticity by $\varepsilon_{a, b} \equiv d \log (a) / d \log (b)$. Furthermore, let $\varphi \equiv b n / \sim V_{2}>0$ stand for the ratio of skilled labour used in setting up firms relative to its use in production. Finally, let relative changes be expressed by a hat. We can then rewrite eq. (6) as

$$
\hat{X}_{2} \quad\left[\varepsilon_{X_{2}, M R_{2}} \cdot \varepsilon_{M R_{2}, p_{2}}\right] \hat{p}_{2} \quad\left[\varphi \cdot \varepsilon_{X_{2}, \tilde{V}_{2}}\right] \hat{n}
$$

We impose that marginal revenue is increasing in the price $\left(\varepsilon_{M R_{2}, p_{2}}>0\right)$, as is the case in most consumer demands with standard properties, ${ }^{5}$ and that $\varepsilon_{X_{2}, M R_{2}}>0$ holds. The first term in eq. $\left(6^{\prime}\right)$ is thus positive and represents the movement along the domestic transform ation curve as the relative price of the manufacturing good increases. This effect of the price increase, hence, makes for an expansion of the manufacturing industry $\left(\hat{X}_{2}>0\right)$, ceteris pari bus. To derive conditions under which an increase in the price of the manufactured good, $\hat{p}_{2}>0$, brings about de industrialization, $\hat{X}_{2}<0$, this term must be more than offset by the second term in eq. $\left(6^{\prime}\right)$, which is negative if $\hat{n}>0$ and represents the effect on output induced by an increase in the number of firms.

If manufacturing production were homothetic, de industrialization $\left(\hat{X}_{2}<0\right)$ could never arise in response to $\hat{p}_{2}>0$, because total output and the number of firms would then

4 Since all varieties are symmetrical, there is just one price in equilibrium. We frequently refer to the monopolistically competitive sector as the 'manufactured good'. Further note that if the small coun try is a net exporter of the manufactured good, the relative price increase represents an improve ment in the country's terms of trade.

5 For a linear demand function $p \quad a \quad b \quad x$, marginal revenue can be written as $\begin{array}{lllllllll}M R & a & 2 b & x & 2 p & a\end{array}$. For this case, the respective elasticity thus reads as $\varepsilon_{M R, p} \quad 2 p /(2 p \quad a)>0$, which must be positive since $\frac{a}{2}<p<a$ in the relevant (elastic) part of the demand curve. 
always change proportionally. In a model with non homothetic production, however, the induced change in the number of firms may cause de industrialization.

Indeed, induced entry $\hat{n}>0$ works against domestic output expansion, because the skilled labour endowment used in production decreases. This decrease in the labour endow ment $\tilde{V}_{2}$ may overturn subject to certain conditions the positive first term in eq. $\left(6^{\prime}\right)$ and lead to a reduction in total output $X_{2}$. For this to happen, the term $\varphi \cdot \varepsilon_{X_{2}, \tilde{V}_{2}}>0$ in eq. $\left(6^{\prime}\right)$ must be large. This term represents a novel generalized Rybczynski effect, which is equal to the standard Rybczynski effect $\varepsilon_{X_{2}, \tilde{V}_{2}}$, weighted by the amount of skilled labour used in setting up firms. From the standard Rybczynski theorem, we know that $\varepsilon_{X_{2}, \tilde{V}_{2}}>1$. This standard Rybczynski effect is magnified if $\varphi>1$, that is, if relatively more skilled labour is used in setting up firms than in production.

To derive conditions under which the price increase entails de industrialization, we pro ceed in three steps. First, we analyze how $\hat{p}_{2}>0$ affects the number of manufacturing firms. Second, in Proposition 1 we state a necessary condition for de industrialization, which involves the change in the output per firm induced by the price increase. Third and finally, we state a necessary and sufficient for de industrialization in Proposition 2.

\subsection{Induced entry in the manufacturing industry}

Our first task is to derive an expression for the induced change in the number of firms. To this end, we totally differentiate expression (5) to obtain

$$
\begin{aligned}
& {\left[\begin{array}{ll}
p_{2} & c_{2}(\cdot)
\end{array}\right] \cdot\left[\frac{\partial X_{2}}{\partial M R_{2}\left(p_{2}\right)} \cdot \frac{\partial M R_{2}\left(p_{2}\right)}{\partial p_{2}} \cdot d p_{2} \quad \frac{\partial X_{2}}{\partial \tilde{V}_{2}} \cdot b \cdot d n\right]+X_{2}(\cdot)\left[\begin{array}{ll}
1 & \frac{\partial M R_{2}\left(p_{2}\right)}{\partial p_{2}}
\end{array}\right] d p_{2}} \\
& b \cdot n \cdot \frac{\partial w_{2}}{\partial M R_{2}\left(p_{2}\right)} \cdot \frac{\partial M R_{2}\left(p_{2}\right)}{\partial p_{2}} \cdot d p_{2}+w_{2} \cdot b \cdot d n
\end{aligned}
$$

where we have used $c_{2}(\cdot) \quad M R_{2}\left(p_{2}\right)$ and $w_{2} \quad w_{2}\left(1, M R_{2}\left(p_{2}\right)\right)$. Rewriting this in terms of relative changes, dividing by $w_{2} \cdot b \cdot n \quad\left[\begin{array}{ll}p_{2} & c_{2}(\cdot)\end{array}\right] X_{2}(\cdot)$, using eq. $\left(6^{\prime}\right)$ and solving for $\hat{n}$ then yields

$$
\hat{n} \quad \frac{\varepsilon_{X_{2}, M R_{2}} \cdot \varepsilon_{M R_{2}, p_{2}} \quad \varepsilon_{w_{2}, M R_{2}} \cdot \varepsilon_{M R_{2}, p_{2}}+\zeta\left(\begin{array}{ll}
1 & \left.\frac{M R_{2}(\cdot)}{p_{2}} \varepsilon_{M R_{2}, p_{2}}\right)
\end{array}\right)}{1+\varphi \cdot \varepsilon_{X_{2}, \tilde{V}_{2}}} \cdot \hat{p}_{2},
$$

where $\zeta \equiv\left(1+\frac{c_{2}(.) X_{2}(.)}{b n w_{2}(.)}\right) \quad\left(\frac{p_{2} \cdot X_{2}(.)}{b n w_{2}(.)}\right)>0$ may be interpreted as the gross value productivity of skilled labour in setting up firms. To gain insights from expression (7), it is useful to inter pret it as a movement along an iso profit line, $\pi \quad\left[\begin{array}{lllll}p_{2} & M R_{2}\left(p_{2}\right)\end{array}\right] X_{2}(.) \quad w_{2} b n \quad \pi\left(p_{2}, n\right)$. Clearly, before and after the increase in $p_{2}$, we must have $\pi\left(p_{2}, n\right) \quad 0$ in the long run. Therefore we can write $d \pi\left(\partial \pi / \partial p_{2}\right) d p_{2}+(\partial \pi / \partial n) d n \quad 0$. Since we know that $\partial \pi / \partial n<0$, it follows that $d n / d p_{2}>0$ if and only if $\partial \pi / \partial p_{2}>0$. The economic interpret ation of $\partial \pi / \partial p_{2}$ is clear cut: it stands for the short run effect of the price increase on the prof itability of the industry (keeping $n$ fixed). In other words, the price increase will induce entry of firms if it raises the short run profitability of the manufacturing industry. The extent of the increase in $n$ depends on the rate of decline of profitability as more firms enter the industry (i.e., $\left.\quad \partial \pi / \partial n\left(1+\varphi \cdot \varepsilon_{X_{2}, \tilde{V}_{2}}\right) w_{2} b\right)$.

The short run effect of the price increase $\hat{p}_{2}>0$ on industry profitability shows up in expression (7) as the three terms in the numerator. We can distinguish the following channels. 
4.1.1 Short run output effect (SOE) Industry profitability rises because an increase in $p_{2}$ implies an increase in $X_{2}$ (keeping the profit margin from production constant), $\varepsilon_{X_{2}, M R_{2}} \cdot \varepsilon_{M R_{2}, p_{2}}>0$. Notice that SOE also shows up as the first term in eq. $\left(6^{\prime}\right)$ which cap tures the industry's overall output change.

4.1.2 Stolper Samuelson effect Industry profitability falls because the increase in $p_{2}$ entails an increase in the price of the factor intensively used in manufacturing, namely, skilled la bour. The rise in $w_{2}$ increases the cost of setting up firms, $\varepsilon_{w_{2}, M R_{2}} \cdot \varepsilon_{M R_{2}, p_{2}}<0 .^{6}$

4.1.3 Profit margin effect Finally, the last term in the numerator of eq. (7) stands for the profit margin effect, weighted by the productivity term $\zeta$. In standard models with constant demand elasticity, this effect would vanish since $\varepsilon_{M R_{2}, p_{2}} \quad 1$. With variable demand elasti city as considered, for example, in Zhelobodko et al. (2012) or Behrens and Murata (2007), however, this term can become either positive or negative, depending on whether the price increase leads to a higher or lower profit margin (mark up) for manufacturing firms.

Notice that from these three effects, the SOE would also arise in standard models from the received literature, which feature homothetic production and constant demand elasti city. The latter two effects hinge on the more flexible set up of our framework. In particu lar, combining these two effects, we may derive the following concept, which captures how the exogenous price increase $\hat{p}_{2}>0$ changes the marginal profitability of setting up manu facturing firms (MPS):

$$
\text { MPS } \quad \zeta\left(1 \frac{M R_{2}}{p_{2}} \varepsilon_{M R_{2}, p_{2}}\right) \quad \varepsilon_{w_{2}, M R_{2}} \cdot \varepsilon_{M R_{2}, p_{2}}
$$

In general, MPS may be positive or negative, depending on whether the price increase has a stronger effect on the mark up in the manufacturing industry or on the factor price of skilled labour, and thereby on the set up costs for manufacturing firms. If MPS is positive, then the increase in $p_{2}$ unambiguously raises profits in the short run, and thus leads to an increase in the number of firms. In the next sub section, we show that MPS is crucial to de termine whether the price increase may also entail de industrialization.

4.2 Decreasing output per firm as a necessary condition for de industrialization Substituting eq. (7) into eq. $\left(6^{\prime}\right)$, rearranging terms, and solving for $\hat{X}_{2}$, we obtain the fol lowing expression

$$
\hat{X}_{2} \frac{\varepsilon_{X_{2}, M R_{2}} \cdot \varepsilon_{M R_{2}, p_{2}}+\varphi \cdot \varepsilon_{X_{2}, \tilde{V}_{2}}\left[\varepsilon_{w_{2}, M R_{2}} \cdot \varepsilon_{M R_{2}, p_{2}} \quad \zeta\left(1 \quad \frac{M R_{2}(\cdot)}{p_{2}} \varepsilon_{M R_{2}, p_{2}}\right)\right]}{1+\varphi \cdot \varepsilon_{X_{2}, \tilde{V}_{2}}} \cdot \hat{p}_{2}
$$

To derive the change in output per firm, $\hat{x}_{2} \hat{X}_{2} \hat{n}$, we subtract eq. (7) from eq. (9). It is straightforward to see that this yields, after some rearrangement,

6 It should be noted that in the present framework there is no presumption of a Jones magnification effect. From standard trade theory we know that $\varepsilon_{w_{2}, M R_{2}}>1$. Yet in our framework we may have $0<\varepsilon_{M R_{2}, p_{2}}<1$, in which case the Stolper Samuelson effect could be less than 1 . 
$\hat{x}_{2} \quad M P S \cdot \hat{p}_{2}$ as given in eq. (8). We can thus state the following intermediate result:

Proposition 1

i. In response to a price increase $\hat{p}_{2}>0$, output per firm falls $\left(\hat{x}_{2}<0\right)$ if and only if $M P S>0$.

ii. $M P S>0$ is a necessary condition for $\hat{p}_{2}>0$ to entail de industrialization $\hat{X}_{2}<0$.

The proof of part i follows immediately from $\hat{x}_{2} \quad M P S \cdot \hat{p}_{2}$. To prove part ii, notice that the second term in the numerator of eq. (9) can be written as $\varphi \cdot \varepsilon_{X_{2}, \tilde{V}_{2}} \cdot$ MPS. Recalling that the first term in the numerator of eq. (9) is positive, which corresponds to the $S O E>0$ mentioned before, de industrialization thus requires $M P S>0$. Stated differently, entry into the manufacturing industry induced by the price increase is a necessary (but not sufficient) condition for de industrialization. Furthermore, it follows from eq. (9) that, given MPS $>0$, this de industrialization is more likely to occur the larger is the generalized Rybczynski effect $\varphi \cdot \varepsilon_{X_{2}, \tilde{V}_{2}}$.

\subsection{Necessary and sufficient condition for de-industrialization}

Turning to the derivation of our main result (Proposition 2), note that the numerator of ex pression (9) is made up of two effects: the direct short run output effect (SOE), and the induced change in the marginal profitability of setting up firms (MPS), weighted by the gen eralized Rybczynski term.

It can readily be seen from expressions $\left(6^{\prime}\right),(7)$, and (9) that the SOE makes for an in crease in the number of firms, because it raises profitability for given firm sizes and thus constitutes an incentive for entry. This is, of course, the standard result of the received lit erature. The interpretation of the second term in the numerator of eq. (9) is straightforward in the light of Proposition 1. It represents the negative (weighted) MPS. We know from Proposition 1(i) that the firm size falls if and only if the term in the square brackets is negative, that is, if the weighted profit margin effect is positive and more than offsets the negative Stolper Samuelson effect. Our main Proposition 2 then follows from rearranging eq. (9) and using the definitions stated before.

Proposition 2 Assume that MPS $>0$. A price increase of the manufactured good $\left(\hat{p}_{2}>0\right)$ then implies de industrialization $\left(\hat{X}_{2}<0\right)$ if and only if $\varphi \cdot \varepsilon_{X_{2} \tilde{V}_{2}}>S O E / M P S$.

Proof Follows from Proposition 1 and expressions (7), (8), and (9).

Propositions 2 is interesting because it highlights the crucial role played by two sets of fac tor intensity conditions familiar from Heckscher Ohlin trade theory. These are the Stolper Samuelson effect in expression (8), and the relative skilled labour intensity in setting up firms as reflected in the novel generalized Rybczynski effect.

We may also state a corollary of Proposition 2, which highlights the crucial role played by the strength of the short run effect of $\hat{p}_{2}>0$ in the occurrence of de industrialization.

Corollary to Proposition 2 The price increase $\hat{p}_{2}>0$ always implies de industrialization $\left(\hat{X}_{2}<0\right)$ if $\varepsilon_{M R_{2}, p_{2}} \rightarrow 0$, that is, if the profit margin effect is extremely strong.

Proof Follows directly from eq. (9), which becomes $\hat{X}_{2} \zeta \cdot \frac{\varphi \cdot \varepsilon_{X_{2}, \tilde{V}_{2}}}{1+\varphi \cdot \varepsilon_{X_{2}, \tilde{V}_{2}}} \cdot \hat{p}_{2}<0$ as $\varepsilon_{M R_{2} p_{2}} \rightarrow 0$. 
In this limiting case, factor prices remain unchanged, and there is no direct short run output effect. Output of the manufacturing industry changes only due to an increase in the number of firms induced by an increase in the profitability of the industry.

Finally notice how the occurrence of de industrialization relates to equilibrium output per firm $x_{2}$. In particular, one may wonder if an increase of the manufacturing price $p_{2}$ implies the 'paradoxical' result of de industrialization whenever $x_{2}$ falls. Yet as is clear from Proposition 1, a fall in firm size is only a necessary but not a sufficient condition for de industrialization.

\section{Conclusions}

In this article, we described a theoretical mechanism how a price increase for the manufac tured good, which may represent a terms of trade improvement, can trigger de industrial ization in a small open economy. We derive the conditions for this seemingly 'paradoxical' outcome, and it turns out that several key ingredients are required for this de industrializa tion to occur.

First, the price increase must raise the short run profitability of and thus trigger entry into the manufacturing industry. This happens if the price change implies a strong increase in the (weighted) profit margin. Second and relatedly, output per firm must fall, so that the manufacturing sector in the economy only expands at the extensive margin, not at the in tensive margin. Finally, fixed set up costs for manufacturing firms in terms of skilled labour must be large, thus leading to a strong generalized Rybczynski effect that we have derived in this article. Notice that this de industrialization could not happen in standard CES mod els with constant demand elasticity, or in models such as Krugman (1979) or Behrens and Murata $(2007,2012 b)$ where trade leads to exit of domestic manufacturing firms and higher output per firm. In our framework, trade may induce entry and imply lower firm output, because we do not impose that preferences must necessarily exhibit pro competitive effects. Rather, as in Zhelobodko et al. (2012), we also allow for the anti competitive case where the elasticity of marginal utility of consumption falls as consumption rises.

As stated before, our model is just one possible theory for de industrialization, though one that is in line with recent empirical evidence on 'premature de industrialization' (Dasgupta and Singh, 2007) and 'productive diversification' (Imbs and Wacziarg, 2003; Rodrik, 2007). Investigating the relative empirical relevance of our theory compared to other frameworks of de industrialization, such as Föllmi and Zweimüller (2008) or Murata (2009), seems to be a very important and fruitful avenue for future research that is well be yond the scope of this short article. Future research should also investigate how our main result generalizes to more complete settings, for example, with more than two factors or even with individual heterogeneity in labour efficiency, as in Behrens and Murata (2012a).

\section{Acknowledgements}

Shortly after the initial submission of this manuscript to Oxford Economic Papers, Albert Schweinberger passed away in August 2013. This is the last paper he wrote in his long and out standing career, and it is dedicated to the memory of this great scholar and friend. We thank James Forder (the editor) and two anonymous referees for very helpful and constructive com ments. We are also very grateful to Kristian Behrens, V. Bhaskar, Sajal Lahiri, and especially Roy Ruffin for various suggestions on an earlier draft. Finally, we are indebted to seminar participants in Rotterdam and Shanghai. 


\section{Funding}

German National Science Foundation (DFG SU 413/2 1) to J.S.

\section{References}

Amir, R. and Lambson, V.L. (2000) On the effects of entry in Cournot markets, Review of Economic Studies, 67, 23554.

Behrens, K., Mion, G., Murata, Y., and Suedekum, J. (2014) Trade, wages, and productivity, International Economic Review, 55, 130548.

Behrens, K. and Murata Y. (2007) General equilibrium models of monopolistic competition: a new approach, Journal of Economic Theory, 136, 77687.

Behrens, K. and Murata Y. (2012a) Globalization and individual gains from trade, Journal of Monetary Economics, 59, 70320.

Behrens, K. and Murata Y. (2012b) Trade, competition, and efficiency, Journal of International Economics, 87, 117.

Bernard, A., Redding, S., and Schott, P. (2007) Comparative advantage and heterogeneous firms, Review of Economic Studies, 74, 3166.

Brandt, L., Rawski, T.G., and Sutton, J. (2008) China's industrial development, in L. Brandt and T.G. Rawski (eds) China's Great Transformation, Cambridge University Press, Cambridge.

Chao, C.C. and Takayama, A. (1990) Monopolistic competition, nonhomotheticity, and the sta bility of the Chamberlinian tangency solution, International Economic Review, 31, 7386.

Chen, Y. and Riordan, M.H. (2007) Prices and variety in the Spokes model, Economic Journal, $117,897921$.

Dasgupta, S. and Singh A. (2007) Manufacturing, services and premature deindustrialization in developing countries: a Kaldorian analysis, in G. Mavrotas and A. Shorrocks (eds) Advancing Development: Core Themes in Global Economics, Palgrave Macmillan, London.

Debande, O. (2006) De industrialization, European Investment Bank Papers, 11, 6482.

Fabinger, M. and Weyl, G. (2013) Pass through as an economic tool: principles of incidence under imperfect competition, Journal of Political Economy, 121, 52883.

Felipe, J. and Estrada, G. (2008) Benchmarking developing Asia's manufacturing sector, International Journal of Development Issues, 7, 97119.

Follmi, R. and Zweimuller, J. (2008) Structural change, Engels consumption cycles and Kaldor's facts of economic growth, Journal of Monetary Economics, 55, 131728.

Helpman, E. (1980) International trade in the presence of product differentiation, economies of scale and monopolistic competition: a Chamberlin Heckscher Ohlin approach, Journal of International Economics, 11, 30540.

Helpman, E. and Krugman, P. (1985) Market Structure and Foreign Trade, MIT Press, Cambridge, MA.

Horn, H. (1983) Some implications of non homotheticity in production in a two sector general equilibrium model with monopolistic competition, Journal of International Economics, 14, 85101.

Imbs, J. and Wacziarg, R. (2003) Stages of diversification, American Economic Review, 93, 6386.

Kaldor, N. (1966) Causes of the Slow Rate of Economic Growth of the United Kingdom, Cambridge University Press, Cambridge.

Kaldor, N. (1967) Strategic Factors in Economic Development, New York State School of Industrial and Labour Relations, Cornell University, Ithaca, NY.

Klepper, S. and Graddy, E. (1990) The evolution of new industries and the determinants of market structure, Rand Journal of Economics, 21, 2744. 
Krugman, P. (1979) Increasing returns, monopolistic competition, and international trade, Journal of International Economics, 9, 46979.

Krugman, P. (1980) Scale economies, product differentiation and the pattern of trade, American Economic Review, 70, 9509.

Lawrence, C. and Spiller, P.T. (1983) Product diversity, economies of scale and international trade, Quarterly Journal of Economics, 98, 6383.

Markusen, J. and Venables, A. (2000) The theory of endowment, intra industry trade and multi national trade, Journal of International Economics, 52, 20934.

McDonough, L. (1992) Homothetic and non homothetic scale economies in applied general equi librium analysis, Canadian Journal of Economics, 25, 196210.

Melitz, M. (2003) The impact of trade on intra industry reallocations and aggregate industry productivity, Econometrica, 71, 1695725.

Melitz, M.J. and Ottaviano, G.I.P. (2008) Market size, trade and productivity, Review of Economic Studies, 75, 295316.

Murata, Y. (2009) On the number and the composition of varieties, Economic Journal, 119, 106587.

Neary, J.P. (2004) Monopolistic competition and international trade theory, in S. Brakman and B. Heijdra (eds) The Monopolistic Competition Revolution in Retrospect, Cambridge University Press, Cambridge.

Neary, J.P. (2009) Putting the new into new trade theory: Paul Krugman's Nobel Memorial Prize in Economics, Scandinavian Journal of Economics, 111, 21750.

Ottaviano, G., Tabuchi, T., and Thisse, J. F. (2002) Agglomeration and trade revisited, International Economic Review, 43, 40935.

Rodrik, D. (2007) Industrial development: stylized facts and policies, in J. Di Sano (ed.) Industrial Development for the 21st Century: Sustainable Development Perspectives, United Nations, New York.

Zhelobodko, E., Kokovin, S., Parenti, M., and Thisse, J. (2012) Monopolistic competition: be yond the constant elasticity of substitution, Econometrica, 80, 276584 